\title{
CONVERSION COATINGS PRODUCED ON AZ61 MAGNESIUM ALLOY BY LOW-VOLTAGE PROCESS
}

\begin{abstract}
The resultes of anodic oxide conversion coatings on wrought AZ61 magnesium alloy production are describe. The studies were conducted in a solution containing: $\mathrm{KOH}(80 \mathrm{~g} / 1)$ and $\mathrm{KF}(300 \mathrm{~g} / 1)$ using anodic current densities of 3,5 and 10 $\mathrm{A} / \mathrm{dm} 2$ and different process durations. The obtained coatings were examined under a microscope and corrosion tests were performed by electrochemical method. Based on these results, it was found that the low-voltage process produces coatings conferring improved corrosion resistance to the tested magnesium alloy.

Keywords: AZ61 magnesium alloy, anodic oxidation, corrosion resistance
\end{abstract}

\section{Introduction}

Magnesium and its alloys are finding increasing use in various industries. This is mainly associated with the growing demand for lightweight structural parts as an immediate result of the introduction of increasingly stringent standards on $\mathrm{CO}_{2}$ emissions. In addition to the low density, other main advantages of magnesium include high mechanical properties, vibration reduction, and good weldability. On the other hand, what limits the scope of magnesium applications is its very high reactivity and susceptibility to corrosion, particularly in media containing chloride ions. Low corrosion resistance of magnesium, compared to aluminium and its alloys, is due to the low voltage potential and lack of tight oxide coatings formed by passivation. The development of new technologies associated with the production of protective coatings on metal surface is expected to contribute to other possible applications of magnesium and its alloys on a large industrial scale [1-3].

The industrial solutions used so far in the production of protective coatings on magnesium and its alloys are based on chromium (VI), which is considered one of the carcinogenic elements. The versatility of chromium application is due to the fact that all technological processes using this element are inexpensive and provide good corrosion resistance. The most common industrial processes are HAE, DOW17 and TAGNITE $[4,5]$, but they all are either based on harmful chromium VI, or require very expensive high-voltage power supplies. Hence the need arises to develop new, more eco-friendly solutions for the surface protection of magnesium, that is, coatings free from the presence of toxic and carcinogenic compounds based on chromium (VI), offering additionally also sound process economy.

Anodic oxidation (anodizing) is one of the most commonly used processes to enhance the corrosion resistance of magnesium. Anodizing is a surface treatment, wherein a layer of oxides is formed by electrolysis on the surface of metal. Anodizing is used for surface protection against corrosion and for decorative purposes. On an industrial scale, plasma electrolytic oxidation (PEO), i.e. anodizing at very high voltages with microarc discharges, is most often used.

The technical literature comprises a number of research works on magnesium anodizing in solutions that do not contain harmful chemicals, but this area is largely dominated by highvoltage technologies [5-7]. The effectiveness of magnesium anodizing depends on parameters such as the chemical composition, and structure and texture of the alloy. Quite important is also the chemical composition of the anodizing bath and parameters of the coating manufacture (time, temperature, anodic current density). Most of the coatings produced by anodic oxidation are fragile, and although useful for the improvement of corrosion resistance, not capable of meeting the requirements of mechanical strength. Hence the need arises for an additional treatment, which is painting of the surface with varnish.

The aim of this study was to produce anodic coatings on the surface of AZ61 magnesium alloy. Coatings described in this study were prepared at a voltage not exceeding $150 \mathrm{~V}$ in a chromium $\mathrm{Cr}$ (VI) - free solution. They were produced at different current densities, using different process durations. The examinations and measurements included coating thickness, surface structure, chemical composition and corrosion resistance.

\section{Test material and methodology}

Studies of the plastic deformation in hot direct extrusion processes were conducted on MgAlZn (AZ61) magnesium alloy. The test material was produced at the Institute of NonFerrous Metals, Light Metals Division (IMN OML), using casting line for ingots made from magnesium alloys for further plastic working. On this line, $100 \mathrm{~mm}$ diameter ingots were cast

\footnotetext{
* INSTITUTE OF NON-FERROUS METALS IN GLIWICE, LIGHT METALS DIVISION IN SKAWINA 19 PILSUDSKIEGO STREET, 32-050 SKAWINA, POLAND

\# Corresponding author: mnowak@imn.skawina.pl
} 
in a semi-continuous cycle [8]. The chemical composition of the test alloy is presented in Table 1. For the purpose of pilotscale tests, $96 \mathrm{~mm}$ diameter billets were prepared, extruded next in a direct system.

The direct extrusion process was carried out on a press of the max. 5MN capacity applying the following parameters: billet preheating temperature $330^{\circ} \mathrm{C}$ to $400^{\circ} \mathrm{C}$, the ram speed from 0.5 to $3 \mathrm{~mm} / \mathrm{s}$, the extrusion ratio 1 from 12 to $25[8,9]$. The extrusion tests have shown that for the AZ61 alloy higher temperature of extrusion is beneficial as it enables reducing the process power consumption and is essential for the rod solutioning heat treatment in an "on-line" system, i.e. on the press handling equipment (the treatment to T5 temper). For the treatment of magnesium alloy products to T5 condition, it is necessary to conduct the extrusion process at a sufficiently high temperature, which allows obtaining full effect of the solution treatment after cooling the alloy directly from the temperature of plastic forming [10]. The obtained test material was characterized by a uniform outer surface, free from cracks and surface melting [11].

The next stage of the research was devoted to the production of protective coatings on the tested parts by anodic oxidation using low voltage technology and solutions without the addition of chromium (VI), which is highly toxic, carcinogenic and irritating to the skin and mucous membranes.

\section{Experimental}

The anodic oxide coatings were produced under galvanostatic conditions in a bath containing potassium hydroxide $(\mathrm{KOH})$ in an amount of $80 \mathrm{~g} / \mathrm{l}$ and potassium fluoride (KF) in an amount of $300 \mathrm{~g} / \mathrm{l}$. All the ingredients were of analytical grade. The volume of the anodizing bath was $1500 \mathrm{~mL}$. Three current densities were applied, i.e. 3, 5 and $10 \mathrm{~A} / \mathrm{dm}^{2}$, and three different times of coating deposition, i.e. 3, 7 and 15 minutes. Stainless steel and AZ61magnesium alloy plates were used as the cathode and anode, respectively. The starting temperature for the process of anodic coating manufacture was $20^{\circ} \mathrm{C}$. Due to the exothermic nature of the coating process, the bath was cooled using a refrigeration unit. Intense stirring of the anodizing bath with compressed air was applied.

TABLE 1

Chemical composition of AZ61 magnesium alloy

\begin{tabular}{|c|c|}
\hline \hline Element & Content in $\mathrm{wt} \%$ \\
\hline $\mathrm{Al}$ & 6.18 \\
\hline $\mathrm{Zn}$ & 0.99 \\
\hline $\mathrm{Mn}$ & 0.246 \\
\hline $\mathrm{Cu}$ & 0.0032 \\
\hline $\mathrm{Ni}$ & 0.0015 \\
\hline $\mathrm{Fe}$ & 0.0023 \\
\hline $\mathrm{Si}$ & 0.033 \\
\hline $\mathrm{Sn}$ & 0.0024 \\
\hline $\mathrm{Be}$ & 0.0005 \\
\hline $\mathrm{Ca}$ & 0.0010 \\
\hline $\mathrm{Pb}$ & 0.0018 \\
\hline
\end{tabular}

\begin{tabular}{|c|c|}
\hline $\mathrm{Cd}$ & 0.00004 \\
\hline $\mathrm{P}$ & 0.0012 \\
\hline $\mathrm{Mg}$ & rest \\
\hline
\end{tabular}

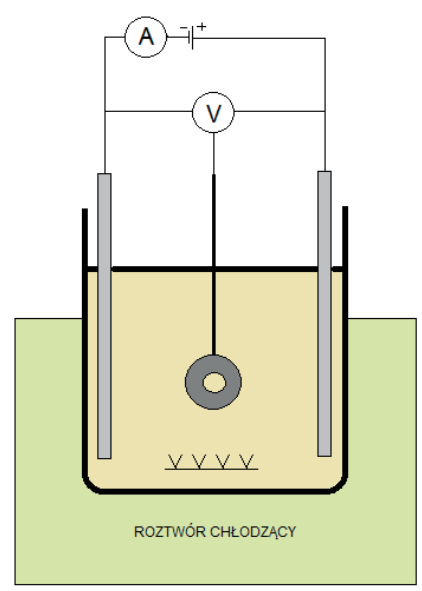

Fig. 1. Schematic picture of a work stand for the manufacture of anodic oxide coatings

Prior to the process of anodizing, magnesium samples were subjected to the following treatments: sand blasting, ultrasonic cleaning with the addition of surface degreasing agent, and pickling at $20^{\circ} \mathrm{C}$ for 5 minutes in a solution of methyl alcohol $\mathrm{CH}_{3} \mathrm{OH}$ and nitric acid $\mathrm{HNO}_{3}$ mixed in a ratio of $5: 1$.

The parameters used in the coating production are shown in Table 2.

TABLE 2

The parameters of magnesium anodizing process

\begin{tabular}{|c|c|c|}
\hline $\begin{array}{l}\text { Time } \\
{[\mathrm{min}]}\end{array}$ & $\begin{array}{l}\text { Initial temperature } \\
\qquad\left[{ }^{\circ} \mathrm{C}\right]\end{array}$ & $\begin{array}{c}\text { Current density } \\
{\left[\mathbf{A} / \mathbf{d m}^{2}\right]}\end{array}$ \\
\hline \multirow{3}{*}{3} & \multirow{7}{*}{20} & 3 \\
\hline & & 5 \\
\hline & & 10 \\
\hline \multirow{2}{*}{7} & & 3 \\
\hline & & 5 \\
\hline \multirow{2}{*}{15} & & 3 \\
\hline & & 5 \\
\hline
\end{tabular}

The corrosion resistance of the obtained coatings were tested by electrochemical method. As a reference served the AZ61 alloy sample without oxide coating. Polarization curves were recorded in a log scale using a PGSTAT 302 corrosion test kit from AUTOLAB placed in a three-electrode glass vessel. The working electrode was AZ61 alloy sample with an area of $2.0 \mathrm{~cm}^{2}$, the reference electrode was $\mathrm{Ag} / \mathrm{AgCl}$ / $3 \mathrm{M} \mathrm{KCl}$ electrode, while counter electrode was made of platinum. The polarisation scan rate was $1 \mathrm{mV} / \mathrm{s}$. Tests started after 10 minute stabilization of the stationary potential under open circuit conditions. As a result of the tests, polarization curves were plotted, and relevant values were used to calculate the corrosion potential $-\mathrm{E}_{\text {corr }}$, corrosion current $-\mathrm{I}_{\text {corr }}$, and polarization resistance $-\mathrm{R}_{\mathrm{p}}$. The tests were conducted in a naturally aerated $\mathrm{NaCl}$ solution at a concentration of $3.5 \%$. 
Electrochemical corrosion tests were carried out on samples produced at the current density of $3 \mathrm{~A} / \mathrm{dm}^{2}$. The test time was 5, 10, 20 and 40 minutes.

\section{Results and discussion}

During the anodizing process, with the increase of voltage, a violent evolution of gas and sparks took place on the surface of magnesium alloy, both these phenomena being considered typical of this process. The result was increase of the solution temperature. Voltage waveforms of the process are graphically presented on Figure 2.

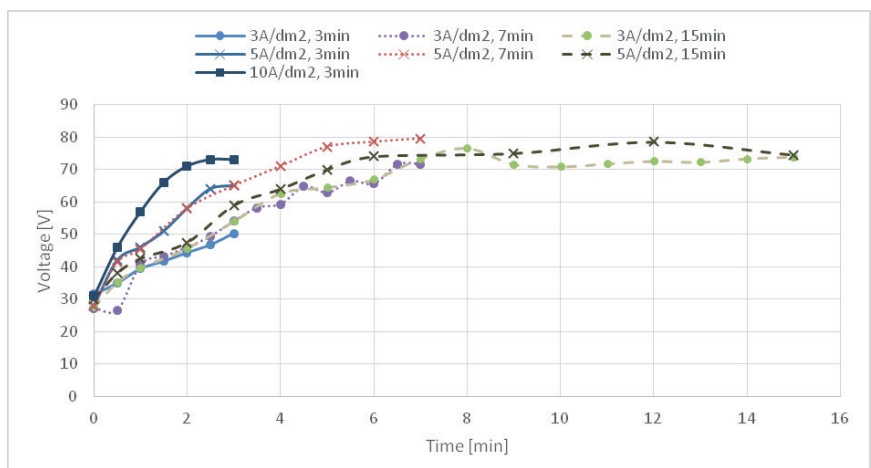

Fig. 2. Voltage waveforms observed during manufacture of anodic coatings on AZ61 magnesium alloy

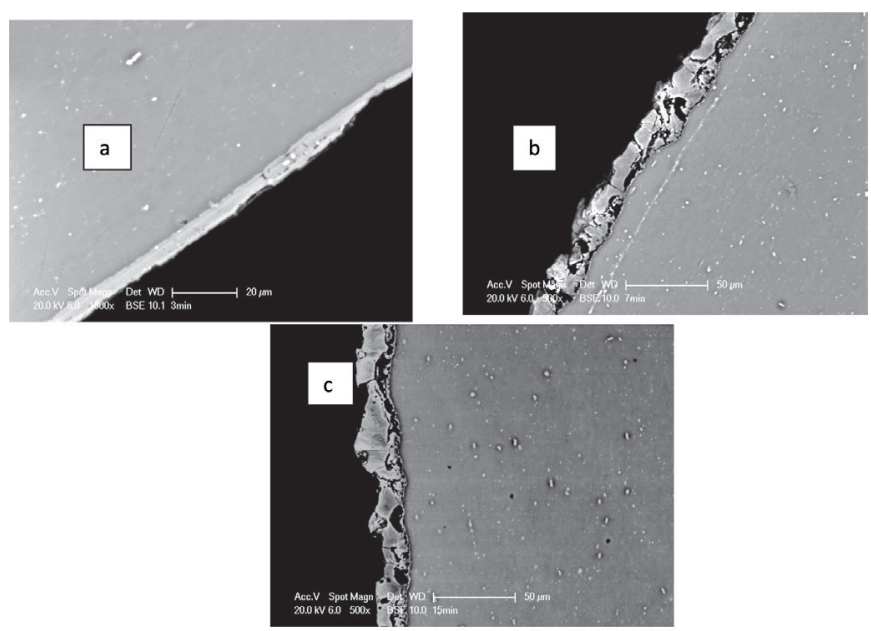

Fig. 3. Cross-sections of anodic coatings produced at a current density of $3 \mathrm{~A} / \mathrm{dm}^{2}$ and process time of: $\mathrm{a}-3 \mathrm{~min} ; \mathrm{b}-7 \mathrm{~min} ; \mathrm{c}-15 \mathrm{~min}$

In all samples, the voltage increased to $70-80 \mathrm{~V}$, and the increase was accompanied by dynamic evolution of gas and sparks on the sample surface, both of which are a characteristic feature of the magnesium anodizing process. Sparking raises the temperature of the solution, and therefore anodizing bath must be subjected to continuous cooling during the anodizing treatment.

Microscopic examinations of anodic coatings were conducted under an OLYMPUS GX71 optical microscope and a Philips XL30 scanning electron microscope.

Analysis of the coating microstructure obtained at a current density of $3 \mathrm{~A} / \mathrm{dm}^{2}$ has proved that longer process time increases not only the coating thickness but also the severity of defects. Sparking accompanying the process of coating manufacture resulted in the formation of numerous defects in the form of cracks and discontinuities. Only coating deposited during the time of 3 minutes was continuous and with a low level of defects.
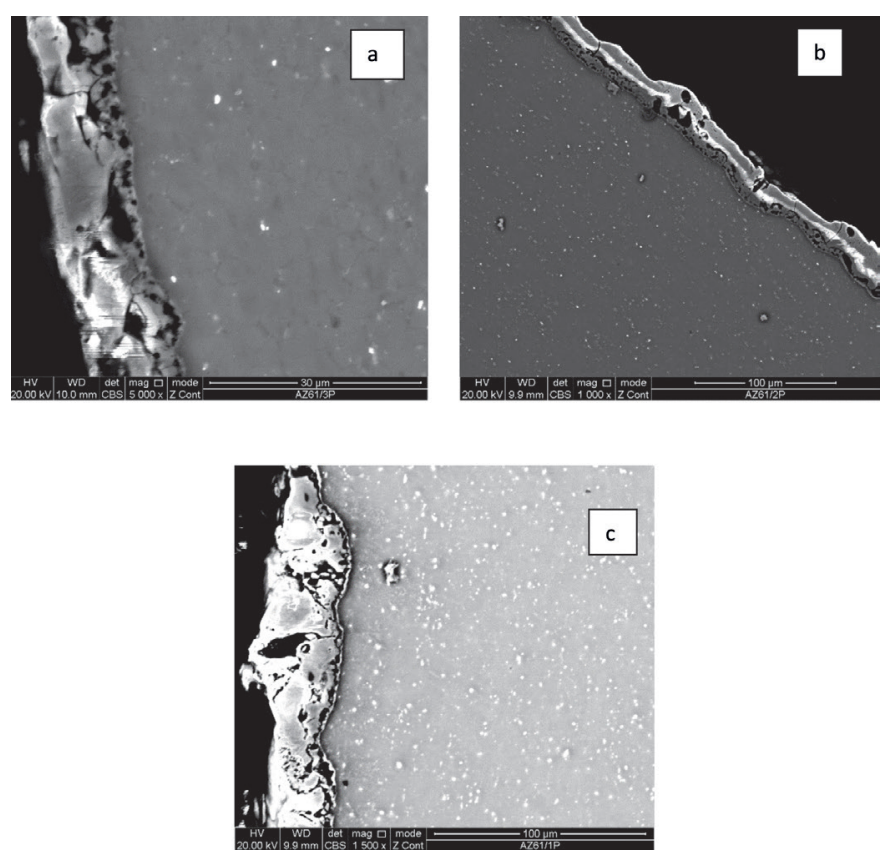

Fig. 4. Cross-sections of anodic coatings produced at a current density of $5 \mathrm{~A} / \mathrm{dm}^{2}$ and process time of: $\mathrm{a}-3 \mathrm{~min} ; \mathrm{b}-7 \mathrm{~min} ; \mathrm{c}-15 \mathrm{~min}$

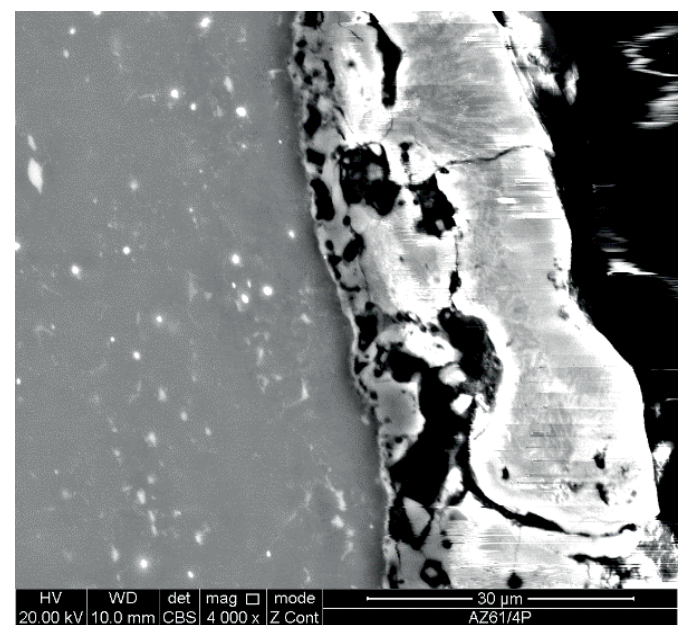

Fig. 5. Cross-section of sample produced at a current density of $10 \mathrm{~A} /$ $\mathrm{dm}^{2}$ and process time of 3 minutes

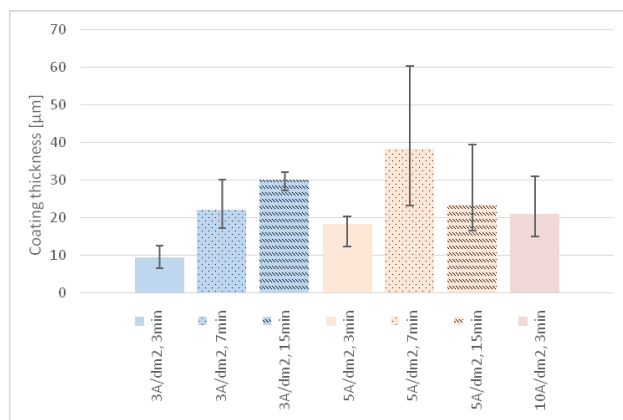

Fig. 6. Thickness of anodic coatings vs process time and anodic current density 
Figure 6 shows plotted relationship between the thickness of anodic coating, process time and applied anodic current density. The thickness of the resulting coatings was between 9 and $38 \mu \mathrm{m}$. The largest thickness of the coating was obtained on the sample produced at a current density of $5 \mathrm{~A} / \mathrm{dm}^{2}$ and process time of 7 minutes, while coating of the

TABLE 3

Sample results of the linear analysis of the chemical composition in microregions

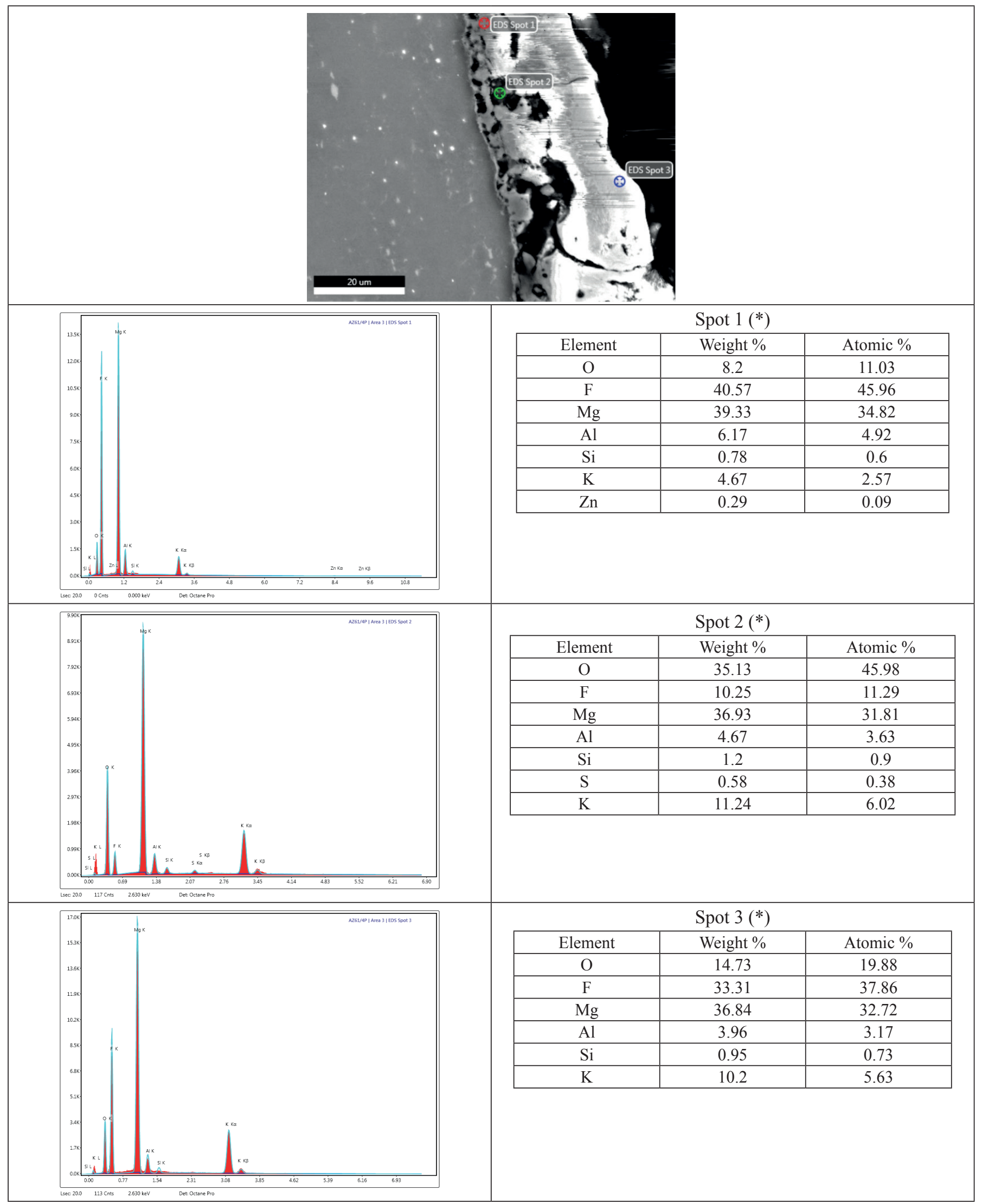


smallest cross-section was formed on the sample produced at $3 \mathrm{~A} / \mathrm{dm}^{2}$ for 3 minutes. The increase in coating thickness with the increasing duration of the anodizing process was observed only when the anodic current density was $3 \mathrm{~A} / \mathrm{dm}^{2}$. Increasing the current density to $5 \mathrm{~A} / \mathrm{dm}^{2}$ has increased the thickness of the coating produced during the time of 3 and 7 minutes. The time of the coating growth prolonged to 15 minutes has resulted in a decrease of the coating thickness. The probable reason was higher temperature of the solution and higher rate of the coating dissolution. A similar phenomenon was observed in the process of anodic oxidation of aluminium and aluminium alloys in solutions based on sulphuric acid.

The obtained coatings were subjected to chemical analysis in microregions to determine the chemical composition by means of scanning electron microscopy. The examinations have revealed that the major components of the coatings were $\mathrm{Mg}, \mathrm{F}, \mathrm{K}, \mathrm{Al}$ and $\mathrm{O}$.

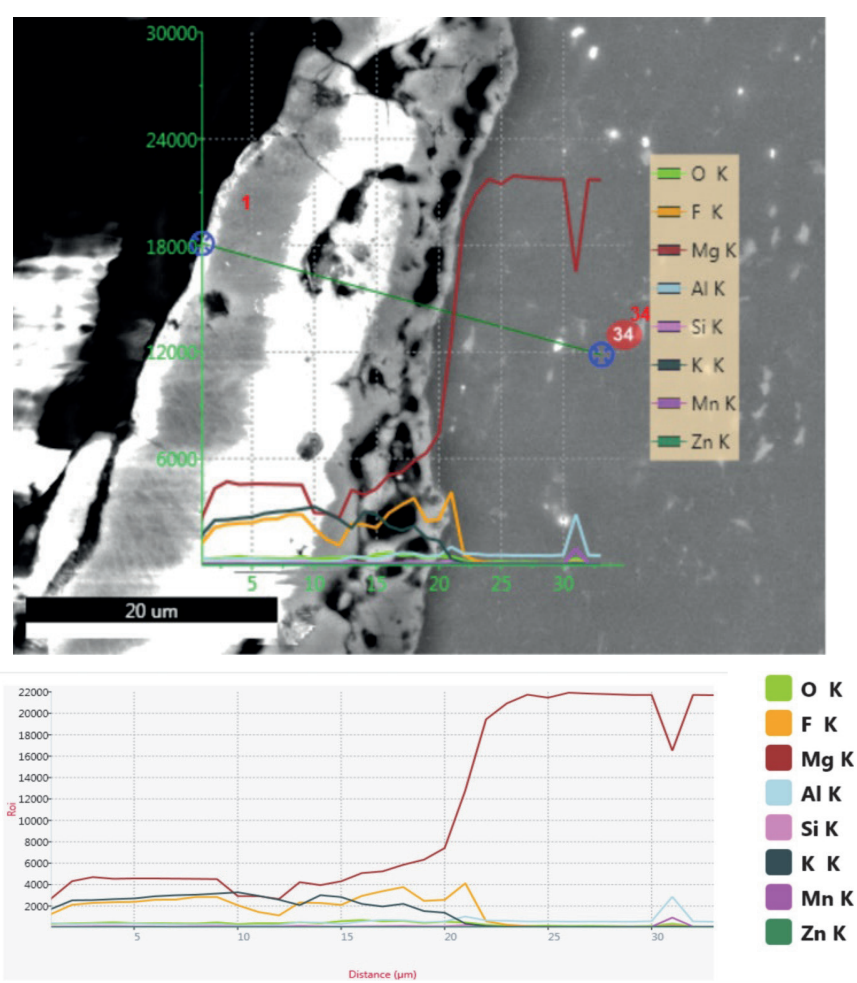

Fig. 7. Sample results of the linear analysis of the chemical composition of anodic coating

The results of corrosion tests are shown in graphic form as polarization curves (Fig. 8) and in tabular form (Table 4). The corrosion tests carried out by electrochemical (potentiodynamic) method have demonstrated the beneficial effect of the process time of 40 minutes on the improvement of coating corrosion resistance. Under these conditions, the corrosion current density decreased to $9.5 \cdot 10-6 \mathrm{~A} / \mathrm{dm}^{2}$ and corrosion potential shifted towards the cathode. Among all the examined variants of the coating process, for this particular variant, the highest value of the polarization resistance was recorded, suggesting an improved corrosion resistance obtained for this coating system.

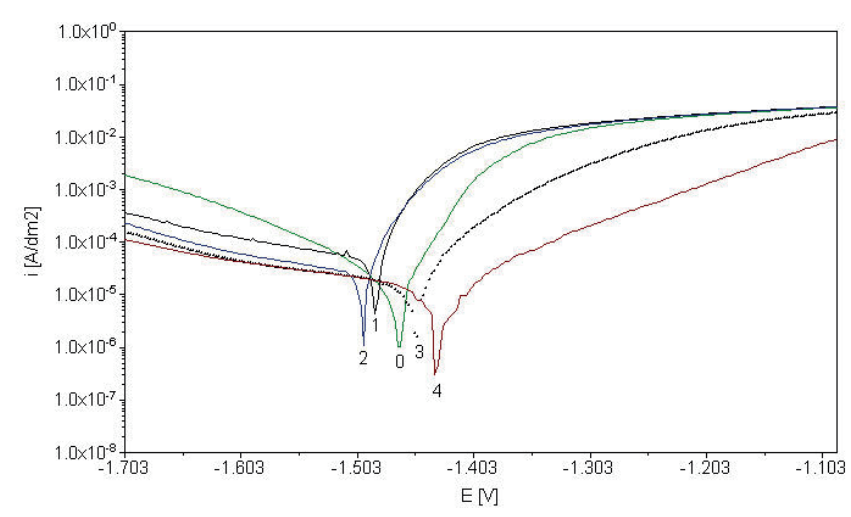

Fig. 8. Polarization curves obtained for the tested AZ61 alloy: 0sample without coating, 1- $5 \mathrm{~min}, 2-10 \mathrm{~min}, 3-20 \mathrm{~min}, 4-40 \mathrm{~min}$.

TABLE. 4

The results of electrochemical tests

\begin{tabular}{|c|c|c|c|}
\hline \hline \multirow{3}{*}{ Sample } & \multicolumn{3}{|c|}{$\begin{array}{c}\text { Results of } \\
\text { electrochemical tests }\end{array}$} \\
\cline { 2 - 4 } & $\begin{array}{c}\mathbf{I}_{\mathbf{c o r r}} \\
{\left[\mathbf{A} / \mathbf{c m}^{2}\right]}\end{array}$ & $\begin{array}{c}\mathbf{R}_{\mathbf{p}} \\
{[\mathbf{\Omega}]}\end{array}$ & $\begin{array}{c}\mathbf{E}_{\text {corr }} \\
{[\mathbf{m V}]}\end{array}$ \\
\hline Without coating & $6,3 \cdot 10^{-6}$ & 69 & -147 \\
\hline $\mathbf{5}$ min & $8,6 \cdot 10^{-6}$ & 70 & -149 \\
\hline $\mathbf{1 0}$ min & $1,2 \cdot 10^{-5}$ & 29 & -149 \\
\hline $\mathbf{2 0} \mathbf{~ m i n}$ & $7,4 \cdot 10^{-6}$ & 127 & -145 \\
\hline $\mathbf{4 0} \mathbf{~}$ in & $9,5 \cdot 10^{-6}$ & 1110 & -144 \\
\hline
\end{tabular}

\section{Conclusions}

As a result of the anodic oxidation of AZ61 alloy, light grey oxide coatings with highly developed surface were produced. The obtained coatings varied in thickness and microstructure. The differences were mainly due to different parameters of the coating production process. At lower current densities $\left(3 \mathrm{~A} / \mathrm{dm}^{2}\right)$, an increase in the coating thickness was observed. Higher current densities and extended process time had a negative effect on the coating thickness growth. The results of corrosion tests have proved that the optimum time for coating growth to obtain the best protection is 40 minutes.

\section{REFERENCES}

[1] A. Stankiewicz, A. Laszczyńska, J. Winiarski, B. Szczygieł, Wybrane metody wytwarzania powłok ochronnych na magnezie i jego stopach, Ochrona przed korozją 53 (4-5) 2010.

[2] Y.Zhang, C.Yan, F. Wang, H.Lou, Study on the environmentally friendly anodizing of AZ91D magnesium alloy, Chunan Cao, Surface \& Coatings technology 161, 36-43 (2002).

[3] R.G. Rateick, Jr.1, Shen-Jiang Xia2, Viola I. Birss2, Sealing methods for enhanced corrosion protectionj of anodized magnesium alloy WE43A-T6, Magnesium Technology 2002.

[4] J.E. Gray, B. Luan, Protective coatings on magnesium and its alloys - a critical review, Journal of Alloys and Compounds 336, 88-113 (2002).

[5] C.S. Wu, Z. Zhang, F.H. Cao, L.J. Zhang, J.Q. Zhang, C.N. Cao, Study on the anodizing of AZ31 magnesium alloys in 
alkaline borate solutions, Applied Surface Science 253 ,38933898 (2007).

[6] El Mahallawy, N.A., Shoeib M.A., Abouelenain M.H., AZ91 Magnesium Alloys: Anodizing of Using Environmental Friendly Electrolytes, Journal of Surface Engineered Materials and Advanced Technology 1, 62-72 (2011).

[7] Li W., Zhu L., Liu H., Preparation of hydrophobic anodic film on AZ91D magnesium alloy in silicate solution containing silica sol, Surface \& Coatings Technology 201, 2573-2577
(2006).

[8] B. Płonka, K. Remsak, M. Nowak, M. Lech-Grega, P. Korczak, A. Najder, Arch Metall Mater 59 377-383 (2014).

[9] B. Płonka, J. Kut, P. Korczak, M. Lech-Grega, M. Rajda, Arch Metall Mater 57 619-626 (2012).

[10] B. Płonka, M. Lech-Grega, K.Remsak, P. Korczak, A. Kłyszewski, Arch Metall Mater, 58, 127-132 (2013).

[11] B. Płonka, K. Remsak, P. Korczak, M. Lech-Grega, M. Rajda, Arch Metall Mater 60, 2967-2970 (2015). 